appraisal of training methods continued, and the variety and scope of internal training was wide, with special emphasis on the training of industrial supervisors. At the Harwell Reactor School, which was attended by 522 students, of whom 26 were from overseas and 262 were Authority staff, two new courses for Authority staff were an extension course in reactor engineering and a course on applied mathematies for engineers; a course for university engineering staff and one for science masters were also held. At the Calder Operations School, where 711 people (213 from overseas) have now attended, standard courses were held for physicists and engineers, and a new course for lecturers at universities and technical colleges.

Some research is included in the Authority's health and safety programme, for example, measurements of radioactivity in air and in rain-water, the study of radiological protection, including the development of instruments for precise measurements of radiation dose-rates down to very low levels and the determination of plutonium in urine and in the body. There was a marked increase in the Authority's commercial activities. Sales of radioisotopes rose from $£ 1.4$ million in $1961-62$ to $£ 1.473$ million, of graphito from $£ 2.843$ million to $£ 3$ million, and of reactor fuel from $£ 9.6$ million to $£ 22.5$ million. This year the chapter on general research discusses the programme as a whole, which, on the basic side, aims to supply fundamental scientific knowledge for future developments of nuclear energy, and also to supply the scientific understanding needed to solve problems arising during the rapid development of the present programme. Much of the general applied research programme is concerned with the interactions of neutrons and other radiations with matter on both the nuclear and atomic scale.

In nuclear chemistry, work continued on the determination, by both radiochemical and mass spectrometric methods, of the proportions of fission product atoms formed with various mass numbers in fission by lowenergy neutrons. In theoretical physics, special attention was directed to investigations of the magnetic and electronic properties of transition metals and their alloys, the properties of defects and defect clusters in metals, and the scattering of neutron beams by liquids and solids. In the physics of the solid-state, the individual atomic contributions to the magnetization of ferromagnetic alloys were identified by neutron diffraction techniques, and the weak magnetic properties of vanadium-chromium alloys, in conjunction with other physical measurements, have established the validity of the band models of electronic structure of these alloys. Other research on radiation damage is now concentrated on elucidating the underlying atomic mechanisms, and at the Atomic Weapons Research Establishment the electrical properties of semiconductors are being exploited to provide a sensitive method for analysing mechanisms of radiation damage. A new variable energy cyclotron is being built at Harwell for general studies on the physical and chemical effects of radiation. Research continues on the physical metallurgy of uranium, plutonium and other metals of technical interest as well as on the physical and chemical properties of the oxides, carbides, nitrides and sulphides of fissile and fertile elements. Besides chemical engineering research in the role of bubbles in gas and solid movement, an extensive programme of research is being undertaken in electronics.

The Culham Laboratory programme remains concerned with stability studies on a wide range of plasma containment systems, including both pinch configurations and magnetic traps. Zeta remains the main toroidal pinch experiment, and has been modified to increase both the initial rate of rise of current in the discharge and the time during which the current is held constant after the initial rise. Besides the study of several linear pinch systems, three methods of injecting particles into a magnetic mirror trap are being studied. Effort has been devoted to the production of computer programmes for magnetohydrodynamic and electromagnetic problems, and a long-term programme of technological studies to support the laboratory's scientific programme has been established.

\title{
BIOLOGY OF RADIOIODINE
}

$\mathrm{T}$ HE Hanford symposium on"The Biology of Radioiodine" was held in Richland, Washington, during July 17-19, under the joint sponsorship of the U.S. Atomic Energy Commission and the Hanford Laboratories of the General Electric Co. (contract No. $A T(45-1)-1350$ between the Atomic Energy Commission and the General Electric Co.). About 150 visiting scientists from Belgium, Canada, France, India, Japan, United Arab Republic, United Kingdom, West Germany and the United States joined more than 70 scientists of Hanford Laboratories for two and a half days of formal presentations and a tour of the facilities of the Laboratories.

Participants were welcomed to the sessions of the first day by Dr. H. A. Kornberg, manager of the Biology Laboratory of Hanford Laboratories. He noted that this symposium on radioiodine was the second in an annual series, the first having been held in May 1962, on the "Biology of the Transuranium Elements", under the general chairmanship of Dr. R. C. Thompson. The third symposium, to be held in the spring of 1964 , will be concerned with the "Biology of Radioactive Particles and Gases" and will be under the general chairmanship of Dr. W. J. Bair.

The symposium was devoted to evaluating the nature, effects and control of radioiodine in the biosphere under the following four general categories:

(1) "Physical Origin and Dispersion of Radioiodine", which covered sources of environmental radioiodine in nuclear industrial operations, accidents and weapons tests, and the nature and form of iodine dispersed and potentially available to the biota.

(2) "Biological Disposition of Radioiodine", which concerned entry of iodine-131 into and passage through biological systems and included uptake of different radioisotopes of iodine by means of various routes of entry in several species of animals, including those in an aquatic environment.

(3) "Biological Effects of Radioiodine", which emphasized comparativo early and late effects of single and prolonged exposure in young and adults of various species and included carcinogenic effects on the thyroid of iodine and $\mathrm{X}$-irradiation.

(4) "Prophylactic and Therapeutic Measures for Radioiodine", covering protective measures to reduce the thyroid uptake of radioiodine or its effects on the thyroid.

Principal fields within these genoral categories were reviewed by authorities and each review paper was followed by brief reports of unpublished work from many laboratories. Only a few of the fifty papers are here summarized.

The session chairmen were Drs. S. A. Lough and H. D. Bruner of the U.S. Atomic Energy Commission, Dr. A. H. Wolff of the U.S. Public Health Service, Dr. B. M. Dobyns of the Cleveland Metropolitan General Hospital, Dr. E. E. Pochin of the University College Hospital Medical School, London, Dr. Stuart Lindsay of the San Francisco Medical 
Center at the University of California, and Dr. C. L. Comar of Cornell University: Dr. Shields Warren was the honorary general chairman.

In a succinct "Statement of the Problem", Dr. H. D. Bruner (Division of Biology and Medicine of the U.S. Atomic Energy Commission) began the scientific sessions by giving a brief history of radioiodine and pointing out the problem areas of concern. Historically, he related, the thyroid was considered a radio-resistant organ, and not many years ago it had been assigned a permissive yearly dose of 30 rems. Following reports of increased thyroid tumour incidence in children as a consequence of exposure to $\mathrm{X}$-irradiation early in life, the Federal Radiation Council recommended a decrease in annual exposure, concluding that a thyroid radiation dose from iodine-131 of $0.5 \mathrm{rem} / \mathrm{year}$ would call for some control measures. As a result, Dr. Bruner pointed out, a dose of $0.5 \mathrm{rem}$ has thus become a limiting case for normal peacetime operation.

J. Z. Holland (Division of Biology and Medicine, U.S. Atomic Energy Commission) comprehensively reviewed the origin and disposition of radioiodine. He compared the relative biological significance of the several radioisotopes of iodine, concluding that even in cases of heavy environmental contamination with the shorter-lived radioiodines, the delays in the food chain would tend to reduce their relative importance, with the result that longer-lived iodine-131 is of unique importance. The availability of parent tellurium (of radioiodine isotopes) could conceivably modify this conclusion; however, data presented at the symposium indicated that tellurium-132iodine-132 would not represent a significant hazard to man following a contamination event involving pastures grazed by cows, etc.

In his review, Mr. Holland pointed out that one may expect extreme irregularity in the distribution of iodine131 following a release incident. This results from the interaction of its relatively high abundance and short half-life with the buoyant rise imparted by the releasing event and the atmospheric eddies and rain clouds acting over periods of a few hours to days. Additional complications are introduced by the behaviour of iodine precursors during releases and by the ehemical behaviour of iodine. Mr. Holland pointed out that iodine reacts with many materials, including trace substances in the atmosphere, and that it is readily oxidized and reduced through a wide range of valence states. The only conclusion which could bo drawn at the present time regarding the partitioning of iodine-131 betweon vapour and particulates, soluble and insoluble forms and among elemental, reduced and oxidized states is that nono is clearly dominant over any great range of conditions. Of interest, too, was Holland's observation that after deposition iodine-131 apparently sublimes and may be re-cycled by means of the atmosphere. However, it was noted by work in two laboratories that up to 90 per cent of the iodine in old fall-out may be in the particulate form, but that the iodine could be quite easily leached, the majority being in the reduced state. Releases from separations plant stacks at Hanford Laboratories were observed to be mainly in a gaseous state for at least 25 miles. Measurements performed at Harwell of stable iodine in the atmosphere indicatod most of it was also in a gaseous state.

Dr. L. Machta (U.S. Weather Bureau) concluded the first session by explaining that three meteorological mechanisms can probably explain all incidents of higherthan-normal iodine-131-levels in the Public Health Sorvice milk survoillance network since September 1961: (1) low. altitude transport of debris from atmospheric and vented underground tests in Nevada; (2) subsidence within an anticyclone; (3) rainout of debris moving in the troposphere or even in the lower stratosphere.

Prof. M. Eisenbud (New York University) pointed out that althorgh there have been about twenty years of large-scale experience with iodine-131, we do not, as yet, have the correct yardstick with which to estimate the dose that would be received by individuals in an environ. ment where the air or water is contaminated with iodine-131. He predicted that direct measurements of the radio-iodine content of milk would be for some time the indicator of choice when it is necessary to appraise the public health significance of environmental contamination by iodine-131.

Two reports dealt with the problem of deposition of iodine on to plants from airborne iodine-131. In the first, Drs. Barry and Chamberlain (Atomic Energy of Canada and U.K. Atomic Energy Authority, Harwell, respectively) stated that the absorption of iodine-132 on to leaves of the broad bean is controlled by the rate of diffusion of the gas through stomata. They found that in dry air the rate of deposition was one-tenth or less that in humid air. Dr. F. P. Hungate et al. (Hanford Laboratories) observed distinctly greater deposition of freshly generated iodine-131 inside leaves as compared with less pure and more particulate-laden off-gas from a melted fuel element. Translocation to other plant parts was slight.

Dr. C. P. Straub and J. H. Fooks summarized some co-operative field investigations involving environmental factors that influenced level of iodine-131 in milk. Of special interest were the results of an investigation performed in co-operation with the St. Louis Health Department. They observed that less iodine-131 was found in the milk of cows grazing well-fertilized pastures.

Under the general subject of "Comparative Uptake of Iodine by Different Species", more than twenty papers were presented. In the area utilizing animals as biological monitors, the work reported extended from using rabbits around the National Reactor Testing Station in Idaho to observations in thyroids of North American deer in many locations and thyroids of pigs in Michigan. The use of the latter species was suggested because their thyroids always showed higher iodine-131 concentrations than the human or foetal thyroids sampled. Substantial uptake of radioiodine by means of the skin was reported. It was noted by workers at Hanford Laboratories that thyroid uptake of iodine-131 after the application of a $\mathrm{Na}^{131} \mathrm{I}$ solution to either a clipped area of skin or to a hairless area of sheep was about a third that observed following oral or parent. eral routes of administration.

Of interest to medical diagnostic laboratories was the report that thyroid metabolic techniques are feasible with small doses of 1-10 nc. iodine-131 using a method described by Dr. M. A. Van Dilla and M. J. Fulwyler (Los Alamos Scientific Laboratory).

A series of papers from the Institute of Industrial Medicine, New York University, included means for estimating the distribution of thyroid doses due to iodine-131 in an exposed population, the dose of iodine-131 to human thyroids in Now York City from nuclear tests in 1962 (up to $40 \mathrm{mrads}$ ) and on thyroid woights of a large number of adults (they suggest a mean weight of $16.7 \mathrm{~g}$, which is less than at present considered for the standard man, that is, $20 \mathrm{~g}$ ).

In a review of several investigations, Dr. G. Gaffney (U.S. Public Health Service) reported, under the general topic of "Radioiodine in Man", that at Brookhaven Drs. S. Cohn and E. A. Gusmano could not detect iodine-131 in thyroids of new-born whose mothers had thyroid burdens up to $230 \mathrm{pc}$. and milk values up to $100 \mathrm{pc}$./qt. Work at Northeastorn Radiological Health Laboratory by Drs. F. Visalli and A. S. Goldin indicated that in children ingestion was the principal mode of entry of iodine-131, and thyroid uptake of iodine-131 could be suppressed but not blocked in children by giving $0.5 \mathrm{mg}$ of iodine-127/day. Moreover, he and his co-workers had found the vehicle of intake of iodine-131 from fall-out was fresh foods, principally milk. However, uptake in man and animals' 
thyroids was similar whether the iodine-131 was in a water solution or in milk, according to Dr. C. L. Comar and co-workers at Cornell.

Dr. R. J. Garner reviewed the available information on the comparative early and late effects of single and prolonged exposure to radioiodine in young and adults of various animal species. He emphasized the work on the animals of economic importance, which included chiefly the sheep, pig and cow, and took special note of the work performed at Hanford Laboratories since 1950 and work at the Compton Research Station on cows by Garner and associates. Garner's review served to point out the radioresistance of the thyroid gland of the domestic animal, with doses in excess of 5,000 rads being required before any sign of damage can be expected to appear.

$H$. Hollister of the Division of Biology and Medicine discussed the problems of estimating the hazards from radioiodine following a nuclear attack. In his paper, $\mathrm{Mr}$. Hollister defined hypothetical nuclear attack situations and considered how information on the deposition and intake of radioiodine would be used to arrive at an estimate of the exposure dose to man and to the effect on grazing animals. He pointed out that interpretable information is needed at dose-levels quite in contrast to those of usual concern for weapons testing and reactor accidents.

Dr. I. Doniach (London Hospital Medical College) then presented a comprehensive review of "The Effects, Including Carcinogenesis, of Iodine-131 and X-rays on the Thyroid of Experimental Animals". Results of various investigators show a similarity in biological action of $\mathrm{X}$-rays and iodine-131 on the thyroid. In the measurement of four different effects, 1,000 rads from $X$-rays has a similar quantitative effect to a calculated mean dose of about 10,000 rads from iodine-131. This comparative effect was somewhat less than the twenty-fold greater effectiveness of $X$-rays compared with iodine-131 reported by Dr. R. O. McClellan and associates at Hanford Laboratories on the early changes scen with these two forms of exposure in sheep. Dr. S. Lindsay, in this samo session, concluded that thyrotropic stimulation after sub-total thyroidectomy is a promoting factor in the development of both benign and malignant thyroid neoplasms in tho rat and that it may also initiate the development of some malignant neoplasms. In an extension of these findings in animals, Dr. E. L. Saenger et al. presented a very complete analytical review of the available data on the carcinogenic effects of iodine-131 comparod with X-irradiation in man. These workers concluded that thyroid carcinoma will only rarely develop with $\mathrm{X}$-ray doses of $2,000-6,000 \mathrm{r}$. after a latent period of $10-35$ years, and that it is probable that $\mathrm{X}$-ray doses of $100 \mathrm{r}$. or greater to children's thyroids will increase the incidence of carcinoma. Irradiation of the adult thyroid with iodine-131 cannot as yet be implicated as a carcinoma-causing mechanism; however, doses of iodine-131 to children seem to increase the susceptibility of their thyroids to neoplastic change. Dr. Saenger stated that the carcinogenic dose-level for a child from iodine-131 would probably not be below 600 rads, considering the differing dose rate between iodine-131 and X-rays, fractionation of dose and irregular distribution.

In the only paper in the sossion devoted to carcinogenic effects of iodino-131 compared with X-irradiation in man, Drs. Dolphin and Beach (U.K. Atomic Energy Estab. lishment, Harwell) reported on a survey of the literature which they had performed. They concluded that the latent period from tumour development appeared to be independent of the thyroid dose in the dose range considered ( $<40,000$ rads), but did show a fairly distinct bimodal responso. They estimated a total thyroid tumour incidence of $3.5 / 10^{6}$ people $/ \mathrm{rad}$.

Dr. F. W. Lengemann, in his roview of "Prophylactic and Therapeutic Measures for Radioiodine Contamination", pointed out that the best policy is to prevent the entrance of iodine-131 into the food chain since this is apparently the major route of contamination for those not occupationally exposed. Because milk appears to be the chief vector of iodine-131 in the United States and some other countries, he proposed four means of limiting the access to the food chain by means of milk: (1) eliminate milk from the diet; (2) using ion-exchange columns to remove radioiodine; (3) feeding milk-producing animals with stored feed; (4) the substitution of fresh milk by stored milk or milk products. An added consideration was the use of thyroid-blocking agents at a number of places in the feed-milk-man cycle. The foregoing possibilities were expanded into an interesting discussion of some of the advantages and disadvantages of each.

Dr. W. J. Bair et al. (Hanford Laboratories) stated in thoir brief paper that the release of stable iodine simultaneously with a release of iodine-131 to reduce the thyroid uptake of iodine-131 is feasible on a biological basis, but that physical and chemical phenomena accompanying the release of iodine vapours must be considered in a final evaluation of this procedure as a method of decreasing the hazard of reactor-released iodine-131.

Dr. Stumpf, reporting on work performed with Prof. E. H. Graul et al. at the University of Marburg, proposed, on the basis of their investigations on elimination of iodine-131 that: (1) a combined treatment with thyroid-stimulating hormone and potassium perchlorate be used to give optimal results at time intervals exceeding $24 \mathrm{~h}$ after administration of iodine-131; (2) gastric lavage (with injection of potassium perchlorate) be used within the first few hours following exposure to iodine-131; (3) ingestion of salivary secretions be avoided.

In the final paper of the symposium, E. C. Watson (Hanford Laboratories), reporting on a co-operative endeavour, noted that increasing the cow's dietary intake of stable iodine to $2 \mathrm{~g}$ /day reduced uptake of iodine-131 by the thyroid of milk drinkers by $50-80$ per cent. Other workers from Hanford Laboratories noted that by increasing the stable iodine content of the diet of the cow from $5 \mathrm{mg}$ to $2 \mathrm{~g} /$ day, levels of iodine-131 in milk decreased by 50 per cent and the cow's thyroid burden was reduced by more than 90 per cent.

One of the highlights of the entire symposium was a very spirited, timoly and thought-provoking banquet speech in which Prof. E. E. Pochin addressed the question: "What is a Permissible Dose?" "Perhaps it is more reasonable to look at what is a permissible risk", ho said, and went on to cite some interesting comparative levels of risk in established industries to-day, based on fatal accidents per year or per million people employed. Prof. Pochin stated that, although we still have a great deal to learn about quantitation of risks in radiation exposure, we have even further to go in attempting to estimate quantitatively the benefits that may be associated with any procedure involving radiation exposure. "In the equation between hazard and benefit", he stated, "it is silly to be tidy-minded about the left-hand side of the equation if we have no figures on the right-hand side with which to compare it. I am sure that more quantitative thinking is needed on the benefits as well as on the risks". Prof. Pochin went on to say that the attempt to set levels of radiation protection on the quantitative basis is very necessary, but a very ambitious one. Many of the difficulties and also criticisms arise simply from the fact that no comparable attempt is boing made to deal as quantitatively with many of the other hazards of life or work. This, in fact, may be one of the greatest values of radiation protection work-it may extend the use of hazard evaluation into other fields and there promote devolopment studies of the justification for risks on a factual basis.

Collectively, the papers presented at this symposium represented the present state of our developing knowledge and should promote proper evaluation of the hazards of radioiodine.
L. K. Bustad 